\title{
Web-Building Strategy of a Wasp Spider, Argiope bruennichi, under Sensory Information Emitted by a Prey Species
}

\author{
Woo Young Jin', Hyun Chul Shin ${ }^{2}$ and Kil Won Kim* \\ ${ }^{1}$ Division of Life Sciences, University of Inchean, Incheon 406-772, Korea \\ ${ }^{2}$ Department of Chemistry Education, Korean National University of Education, Chungbuk 363-791, Korea
}

Received April 8, 2011 /Revised April 26, 2011 /Accepted April 26, 2011

\begin{abstract}
Web structure of spiders is a foraging strategy as well as an investment to get prey. In order to increase the fitness consequence, spiders change their foraging strategy based on sensory information provided by prey species. We conducted an experiment to demonstrate whether an orb-web building spider, Argiope bruennichi modifies its web-building behavior after experiencing sensory information emitted by a UV recognizing flying insect, Bombus terrestris. To know how the web structure would be modified, we observed web characteristics after providing sensory information of a potential prey species, the bumblebee (experimental group) and compared them to the control group (no information provided). We hypothesized that the spiders of the experimental group would increase investments in their web construction and stabilimentum decoration. The results rejected our hypothesis. Web and stabilimentum constructions decreased in the course of the experiment in both the control group and the experimental group. The individuals did not increase their stabilimentum length and did not extend their web areas, in spite of sensory information given by the nectar collector.
\end{abstract}

Key words : Web-building behavior, prey, sensory information, Argiope, bumblebee

\section{서 론}

개체를 둘러싼 환경에서 제공되는 감각 정보(sensory information)를 토대로 동물들은 끊임없이 그들의 행동을 수정 해야 한다. 환경 요인은 예측하기 어렵고 늘 변화하기 때문이 다. 정확한 정보의 수신과 이를 바탕으로 한 행동의 수정은 개체의 생존과 번식에 직접적으로 영향을 미치기 때문이다[5]. 먹이를 효율적으로 획득하는 동물은 그렇지 못한 동물에 비해 서 생존과 번식의 기회를 늘릴 수 있다. 감각 정보를 제공하는 개체(signaler)와 감각 정보를 수집하는 개체(receiver)가 피식 자(prey)와 포식자(predator)의 관계에 놓이는 경우 이 문제는 심각하다. 피식자는 포식자에게 자신의 정보를 노출시키지 않 아야 하겠지만 포식자의 입장에서는 피식자, 즉 먹이로부터 오는 감각 정보를 정확하게 해석하고 포식을 위한 전략 수립 에 반영해야 할 것이다[21].

거미는 육상의 대표적인 포식 동물로 주어진 환경에서 제공 되는 여러 가지 정보를 바탕으로 자신의 포식 전략을 수정한 다 $[16,17,20]$. 특히 웹 건축 행동은 거미 종의 대표적인 포식 전략으로서 이 중 정주성(sedentary) 거미의 웹 건축 행동은 개체의 적응도(fitness)를 높이기 위한 에너지 투자 전략이다 [24]. 비록 거미의 건축 행동은 진화적 구속에 의해 제한적인 양상을 보이지만 주어진 생물, 비생물적 환경 요인에 따라서

*Corresponding author

Tel : +82-32-835-8258, Fax : +82-32-835-0763

E-mail : kilwon@incheon.ac.kr
가변성을 보일 수 있다[7,9,10,12]. 먹이로부터 오는 감각 정보 를 수용하고 웹 변인을 수정하는 행동을 보이는 거미 개체는 그렇지 않은 개체에 비해 생존과 번식에 유리할 것이다[3]. 피 식자를 포함해 주변의 생물종으로부터 제공되는 감각 정보를 토대로 웹 건축 전략을 수정하는 행동은 거미가 자신의 이익 을 극대화하는 전략이라고 볼 수 있다. 이익 극대화에 근접하 기 위한 거미 웹의 물리적 구조를 정량화 할 수 있다면, 윕 변인을 통한 최적 포식자의 포식전략 수립을 예측하는 것이 가능할 것이다.

Wise와 Barata [26]의 연구와 Opell [14]의 연구에 따르면, 포식에 성공할 가능성이 많은 조건에서 더 많은 포식을 원하 는 개체는 보다 큰 웹을 건축하고자 할 것이다. 또한 공중에 둥근 웹을 건축하는 일부 거미들이 건축 과정 후반부에 웹 위에 장식처럼 추가하는 지그재그 형태의 흰띠줄('stabilimentum')이 있다. 이 흰띠줄 건축 행동이 거미가 먹이를 효과 적으로 포획하기 위한 투자 행동이라는 가설이 있다. 흰띠줄 기능에 관한 이른바 '먹이유인 가설(prey-attraction hypothesis)'에 지지적인 근거를 제시하는 Craig와 Bernard [4]의 연 구와 Tso [25]의 연구에 따르면, 자외선 반사율(UV reflectance)이 높은 흰띠줄의 건축은, 곤충이 진화적 적응을 통 해 내재적으로 이미 가지고 있는 감각 편향(sensory bias)을 이용한 유인 전략이라는 것이다. 즉, 꽃의 중앙 부위에서 반사 되는 자외선을 인식하여 날아오는 꽃꿀 채집 곤충들이 흰띠줄 에서 반사되는 자외선에 유인된다는 것이다. 꽃꿀을 채집하는 초식 곤충은 꿀벌의 경우처럼 꽃꿀을 가진 식물의 특성(모양, 
색깔, $\mathrm{UV}$ 흡수 및 반사, 냄새 등)에 더 잘 반응하는 감각 편향 을 가지고 있는 것으로 보인다[13,18]. 실제로 흰띠줄은 일반 거미실에 비해 높은 자외선 반사율을 나타낸다[2]. 또한 적지 않은 연구들이 흰띠줄을 포함한 웹이 흰띠줄이 없는 웹과 비 교해 꽃꿀채집자(nectar collector)를 사낭하는 일에 더 성공적 이었음을 보여주고 있다[6,23].

긴호랑거미(Argiope bruennich)는 논습지와 관목 나대지에 많이 서식하는 종으로 공중에 둥근 형태의 웹을 건축하고 종 종 웹 위에 흰띠줄 장식을 추가하는 건축행동을 보인다. 이유 는 정확히 밝혀지지 않았지만 때때로 흰띠줄이 없는 웹을 건 축하기도 한다. 꽃꿀을 채집하는 서양뒤영벌(Bombus terrest$r i s)$ 은 화분을 매개하는 대표적인 곤충이며, 긴호랑거미 $(A$. bruennichi)의 웹에 쉽게 걸릴 수 있는 먹이종이다. 비행하는 화분 매개 곤충을 사냥하기 위해 웹을 건축하는 개체는 그에 적합한 건축 전략을 수립해야 할 것이다. 다시 말해, 특정한 먹이종으로부터 제공되는 감각 정보가 있는 환경에서 거미는, 그러한 감각 정보가 전혀 없는 환경에서와는 다른 구조를 가 지는 윕을 만드는 것이 자원 투자의 효율성 차원에서 유리할 것이다. 먹이 동물로부터 제공되는 감각 단서(sensory cue)는 먹이 포획이 실제 일어나지 않는다고 하더라도, 거미가 포식 전략을 세우는데 중요한 정보를 줄 것이다. 실제 crab spiders [11], funnel-weaving spiders [19], orb-weavers [15], wolf spiders [16] 등의 적지 않은 거미들이 먹이로부터 제공되는 감각 정보를 받아들인다는 가설에 지지적인 연구 성과들이 있다.

따라서 본 연구는 다음과 같은 가설을 제안한다. 먹이종에 대한 감각 정보가 없는 환경에 놓인 개체와 비교해, 비행성이 고 자외선(UV) 인식에 민감한 서양뒤영벌(B. terrestris)의 감각 정보를 제공받은 긴호랑거미(A. bruennich)는 웹 건축 전략 차이를 보일 것이다. 지상에서 보다 높은 위치에 웹을 건축할 것이고, 포식 성공 가능성의 증가에 따른 웹 건축 빈도의 증가 와 더불어 웹 넓이가 증가하며, 흰띠줄 건축 빈도 또한 증가할 것이라는 가설을 설정하였다.

\section{재료 및 방법}

\section{연구종: 긴호랑거미(Argiope bruennichi)와 서양뒤영벌} (Bombus terrestris)

긴호랑거미(Argiope bruennichi)는 대표적인 논거미로서 다른 Argiopespp.에 비해 상대적으로 쉽게 관찰되는 종이다. 성체뿐 만 아니라 미성숙 개체들도 지상에서 쉽게 관찰된다. 또한 개체 가 웹의 중심(hub)에 주로 위치하고 있어 채집이 용이하다. 실 험실 환경에서도 잘 사육되는 것으로 관찰되었다. 성체 출현 시기는 7월-10월이다. 둥근 모양의 웹(orb web)을 건축하며, 중 앙에 특이적 웹 부속물(web decoration)인 UV 반사율이 높은 흰띠줄(stabilimentum)을 건축한다. 성체의 흰띠줄은 웹의 중 앙을 가로질러 일자형으로 건축하는 것이 일반적이며, 아성체
의 경우 나선형(spiral) 등의 이형적인 형태를 보이기도 한다. 서양뒤영벌(Bombus terrestris)은 한국과 유럽 등지에 분포하 며 자외선(UV) 인식이 매우 높은 종으로서 전 세계적으로 화 분 매개 곤충(pollinator)로서의 이용 빈도가 매우 높다. 성충 은 6-7월부터 나타나며, 꽃의 분포율이 높은 들판 지역에서 긴호랑거미(A. bruennichr)와 같은 정주성 거미에게 적합한 먹 이종이다.

\section{채집 및 사육}

긴호랑거미(A. bruennichr) 암컷 성체를 채집하였다. 장소는 인천광역시 남동구 논현동에 위치한 소래 습지 생태 공원 일 대 $\left(37^{\circ} 24^{\prime} 29.09^{\prime \prime} \mathrm{N}, 126^{\circ} 44^{\prime} 49.07^{\prime \prime} \mathrm{E}\right)$ 이며, 8월 12일, 23일, 29일 3 회에 걸쳐 오전 중(09:00-11:30)에 채집하였다. 채집된 개체는 개별적으로 실험을 위해 디자인된 사육 상자에 넣어졌다(Fig. 1). 서양뒤영벌(B. terrestris) 군집(colony)은 한국유용곤충연구 소에서 제공받아 사용하였다.

사육실은 $12 \mathrm{hr} / 12 \mathrm{hr}$ (낮: 08-20시(663-734 lux), 밤: 20-08 시)의 일주기를, $29.5-31^{\circ} \mathrm{C}$ 의 온도를, $69.8-72.2 \%$ 의 습도를 유 지하였다. 분무기를 사용하여 $70^{\circ} \mathrm{C}$ 의 증류수를 매일 12 시와 17 시에 2 회, 사육 상자 상단에 3 번, 하단에 3 번 분사하였다. 또한 실험기간 중에 먹이 공급과 연구진 외에 타 생물종에 속하는 개체의 출입을 차단하였다.

파리목 동애등에(Ptecticus tenebrifer)를 개체 당 4 마리씩 먹 이 자극을 차단하는 실험 기간에 들어가기 앞서 24시간 전에 먹이로 제공하였다. 동애등에는 $45-60 \mathrm{mg}$ 의 몸무게(body mass)를 가진다. 이 과정은 실험 기간 동안 개체의 수명 (longevity)을 늘리기 위해서 수행되었다.

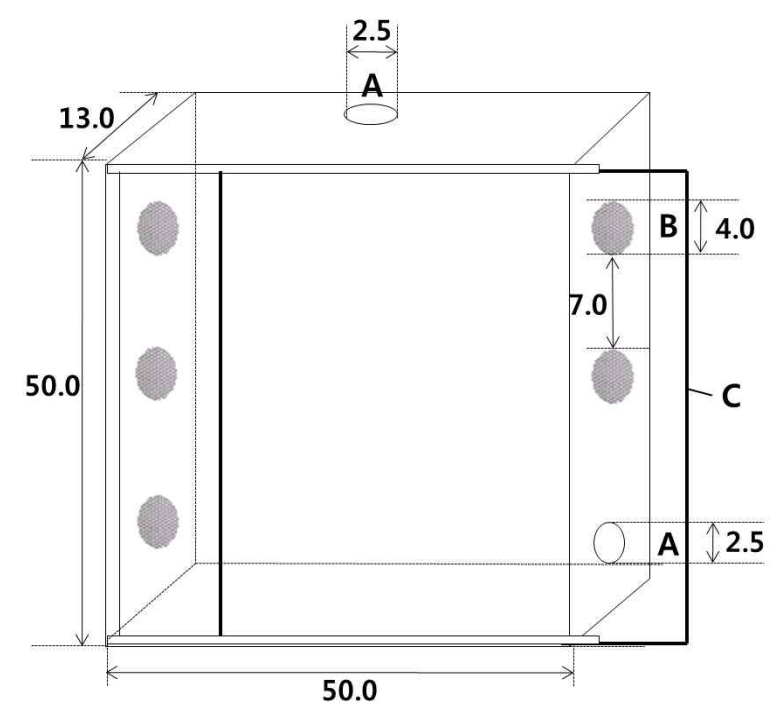

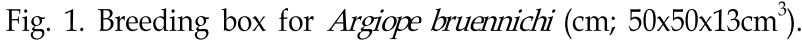
It is made from acryl material. A: hole for prey provision, B: wire meshed hole for ventilation, C: transparent sliding door for observation. 


\section{실험 설계}

대조군(control group) 34개체, 실험군(experimental group) 37 개체가 실험에 사용되었다. 대조군과 실험군에 대한 실험은 감각 정보의 차단을 위해 각각 격리된 실험실에서 수 행되었다. 대조군 개체에게 실험 기간 동안 먹이를 공급하지 않았으며 먹이에 대한 감각 정보 또한 제공하지 않았다. 먹이 감각 정보가 제공되지 않은 기간은 모든 개체에게 총 6일(144 시간)이다.

실험군에 속한 개체에게도 실험 기간(6일) 동안 먹이를 공급하지 않았다. 처음 3일(72시간)은 먹이 자극이 주어지지 않는 환경을 제공하였고, 이어지는 3일은 서양뒤영벌(B. terrestris)의 감각 정보(sensory information)만이 제공되는 상 황을 만들었다(Fig. 2). 정보 제공은 오전 9시를 시작으로 1 시간 동안 이루어졌으며 이어지는 1 시간 동안은 아무런 정 보를 제공하지 않았다. 정보가 제공되는 시간과 제공되지 않는 시간을 총 4 회 반복하였다. 정보 제공이 끝난 $16: 00$ 로 부터 1 시간 뒤인 $17: 00$ 에 이전에 건축된 웹을 모직 천을 이 용하여 제거한 후 다음날 08:00에 건축된 웹을 영상 촬영하 고 변인을 측정하였다.

\section{웹 변인 측정}

실험 기간 동안 오전 8 시에 대조군과 실험군에서 웹을 건축 한 개체와 건축하지 않은 개체가 기록되었다. 흰띠줄의 경우 는 웹 중심(hub)에서 상단(upper area)과 하단(lower area) 둘 중 한 지역에서만 흰띠줄이 관찰되어도 흰띠줄을 건축한 것으 로 간주하고, 선형(linear)이 아닌 일반 실크의 색깔과 구분이 되지 않는 색이 희미한 안개형 웹 부속물은 흰띠줄을 건축하 지 않은 것으로 간주하였다.

웹의 높이는 사육장의 바닥으로부터 건축된 웹의 중심까지 의 최단 거리로 측정하였다. 웹의 중앙에서 가장 먼 거리에 있는 마지막 원그물(spiral)까지의 거리인 장반경(longer radi-
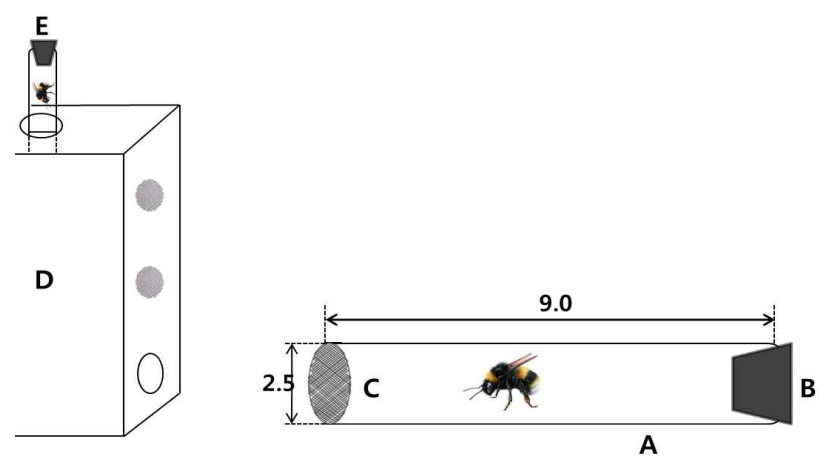

Fig. 2. Method used to provide sensory information emitted by Bumbus terrestris $(\mathrm{cm})$. A: transparent acryl tube, B: gum stopper, C: wire meshed window, D: breeding box $\left(50 \times 50 \times 13 \mathrm{~cm}^{3}\right), \quad$ E: hole for sensory information provision.

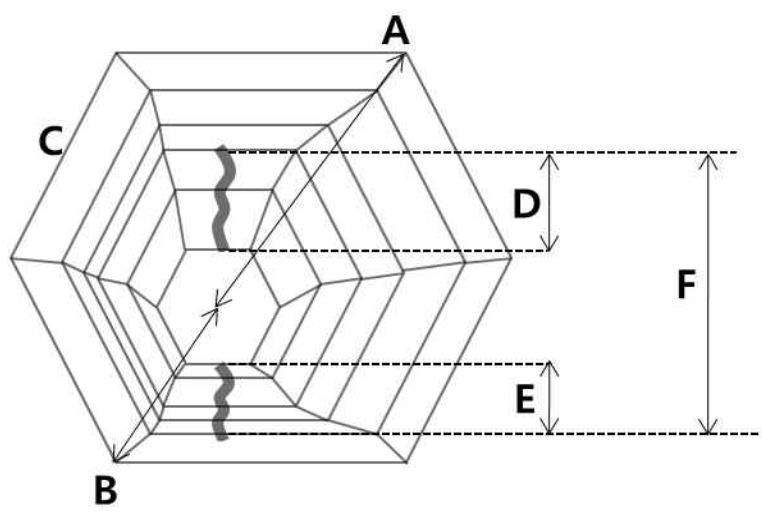

Fig. 3. Measurement of the web structure. A: longer radius, B: shorter radius, C: spirals, D: upper stabilimentum length, E: lower stabilimentum length, F: total stabilimentum length.

us)과 가장 가까운 마지막 원그물까지의 거리인 단반경 (shorter radius)을 측정하고 이를 바탕으로 웹 면적(web area) 을 산출하였다. 즉, 장반경과 단반경의 평균값을 반지름 $(\mathrm{r})$ 으 로 하고 계산한 원의 넓이 $\left(\pi \mathrm{r}^{2}\right)$ 를 웹의 면적으로 간주하였다 (Fig. 3). 원그물 개수는 장반경의 범위에 포함되는 웹의 중앙 에서 가장 먼 거리에 있는 마지막 점착실까지 존재하는 모든 나선실의 개수이다. 상단 흰띠줄 길이(upper stabilimentum length)와 하단 흰띠줄 길이(lower stabilimentum length), 흰 띠줄 전체 길이(total stabilimentum length)를 측정하였다 (Fig. 3).

\section{통계 분석}

대조군과 실험군에서 각 개체의 웹 건축 구조 변화의 통계 적 분석을 위해, 동일한 표본에 대한 반복 측정치를 비교하기 위해 SYSTAT version 12 [22]에 의해 제공되는 비모수통계검 정법(non-parametric statistical hypothesis test)인 Wilcoxon signed-rank test를 사용하였다.

\section{결 과}

웹을 건축한 개체의 수를 비교한 결과 대조군과 실험군에서 모두 전반적으로 감소하는 경향을 보였다(Table 1). 대조군에 서 웹을 건축한 개체의 비율이 자극 전일(previous day: 개체 가 굶은 지 3 일째 되는 날)과 자극 1 일(sensory day1: 실험군의 경우 첫 번째 서양뒤영벌 자극이 주어진 날이며, 대조군의 경 우 굶은 지 4 일째 되는 날) 사이에 $11.8 \%$ 가 감소한 데 비해, 실험군의 경우 자극 전일과 자극 1 일에서 웹을 건축한 개체의 비율이 대조군과 비교하여 약 두 배인 $21.6 \%$ 가 감소한 것으로 나타났다. 자극 1 일과 자극 2 일(sensory day2: 실험군에서 두 번째 자극이 주어진 날이며, 대조군에서는 개체가 굶은 지 5 일 째 되는 날) 사이에 대조군의 경우 $11.8 \%$ 감소하였고, 실험군 
의 경우 $16.2 \%$ 의 감소 경향을 보였다. 자극 2 일과 자극 3 일에 대조군의 경우 웹을 건축한 개체의 비율이 $5.9 \%$ 증가하는 양 상을 보였으며, 실험군의 경우 대조군에 비해 약 2 배 증가한 $10.8 \%$ 의 증가 양상을 보였다.

흰띠줄을 건축한 개체 수 비교 결과 대조군과 실험군 모두 전반적으로 감소하는 경향을 보였다(Table 1). 대조군에서 흰 띠줄을 건축한 개체의 비율이 자극 전일에서 자극 1 일에 $14.7 \%$ 감소 경향을 보였으며, 실험군에서 흰띠줄을 건축한 개 체의 비율은 자극 전일에서 자극 1 일에 대조군의 약 두 배인 $27.0 \%$ 의 감소 경향을 보였다. 자극 1 일과 자극 2 일에 대조군의 경우 $14.7 \%$ 로 이전의 흰띠줄 건축 비율 감소 양상과 유사한 비율의 감소 양상을 보였으며, 실험군의 경우 $21.6 \%$ 의 감소 양상을 보였다. 자극 2 일과 자극 3 일에 대조군의 경우 $5.9 \%$ 의 적은 흰띠줄 건축 빈도 감소 양상을 보였으나 꾸준한 감소 양상을 보였고, 이와 반대로 실험군의 경우 흰띠줄 건축 빈도 가 $10.8 \%$ 증가 양상을 보였다.

웹의 높이는 대조군과 실험군 모두 유의미한 증감 양상이 나타나지 않았다(Table 2). 전일과 자극 1 일의 비교, 자극 1 일 과 자극 2 일의 비교, 자극 2 일과 3 일의 비교 모두에서 통계적 으로 유의미한 차이를 보이지 않았다(Wilcoxon signed-rank test: $p>0.05)$.

웹 면적의 경우는 대조군과 실험군에서 모두 뚜렷하게 증가 하거나 감소하는 경향을 보이지 않았다(Table 3). 감각 자극이 제공된 날들 간에 나타난 증가 또는 감소 경향이 통계적으로 유의미하지 않은 것으로 나타났는데(Wilcoxon signed-rank test: $p>0.05)$, 유일하게 실험군에서 전일과 자극 1 일 간에 90.52 $\mathrm{cm}^{2}$ 다소 감소하는 경향을 보였다 $(\mathrm{t}=2.516, p=0.016)$.

원그물 개수는 대조군과 실험군에서 모두 뚜렷하게 증가하 거나 감소하는 경향을 보이지 않았다(Table 4). 다만 자극 전일 과 자극 1 일의 비교에서 두 그룹 모두에서 원그물 개수가 감소 하는 경향을 나타냈다. 즉, 자극 전일과 자극 1 일에 대조군의 경우 평균 개수 6.86개 감소하는 경향이 나타났으며(Wilcoxon signed-rank test: $\mathrm{t}=2.147, p=0.033)$, 실험군의 경우 평균 개수 가 1.71 개 감소하는 경향이 나타났다 $(\mathrm{t}=2.431, p=0.015)$.

상단 흰띠줄 길이(upper stabilimentum length) 변화 양상 을 관찰한 결과 실험군과 대조군 모두에서 전반적으로 감소하 는 경향이 나타났다(Table 5). 자극 전날과 자극 1 일에서 대조 군의 경우 평균값이 $0.49 \mathrm{~cm}$ 증가하는 경향을 보였으나 (Wilcoxon signed-rank test: $\mathrm{t}=2.46, p=0.010)$ 실험군의 경우 $0.36 \mathrm{~cm}$ 감소하는 경향을 보였다 $(\mathrm{t}=2.356, p=0.024)$.

Table 1. Comparison of the number of individuals that constructed its web and stabilimentum between control group and experimental group

\begin{tabular}{llcccc}
\hline & & Previous day & Sensory day 1 & Sensory day 2 & Sensory day 3 \\
\hline \multirow{3}{*}{$\begin{array}{l}\text { Web } \\
\text { Construction }\end{array}$} & Control group & $64.71 \%$ & $52.94 \%$ & $41.18 \%$ & $47.05 \%$ \\
& $(\mathrm{n}=34)$ & $(\mathrm{n}=22)$ & $(\mathrm{n}=18)$ & $(\mathrm{n}=14)$ & $(\mathrm{n}=16)$ \\
& Experimental group & $75.68 \%$ & $54.05 \%$ & $37.83 \%$ & $48.65 \%$ \\
& $(\mathrm{n}=37)$ & $(\mathrm{n}=28)$ & $(\mathrm{n}=20)$ & $(\mathrm{n}=14)$ & $(\mathrm{n}=18)$ \\
\hline \multirow{4}{*}{$\begin{array}{l}\text { Stabilimentum } \\
\text { construction }\end{array}$} & Control group & $58.82 \%$ & $44.12 \%$ & $29.41 \%$ & $23.53 \%$ \\
& $(\mathrm{n}=34)$ & $(\mathrm{n}=20)$ & $(\mathrm{n}=15)$ & $(\mathrm{n}=10)$ & $(\mathrm{n}=8)$ \\
& Experimental group & $72.97 \%$ & $45.95 \%$ & $24.32 \%$ & $35.14 \%$ \\
& $(\mathrm{n}=37)$ & $(\mathrm{n}=27)$ & $(\mathrm{n}=17)$ & $(\mathrm{n}=9)$ & $(\mathrm{n}=13)$ \\
\hline
\end{tabular}

Table 2. Comparison of the web height between control group and experimental group ( $\mathrm{cm}$; mean $\pm \mathrm{SD})$

\begin{tabular}{lcccc}
\hline & Previous day & Sensory day 1 & Sensory day 2 & Sensory day 3 \\
\hline Control group $(\mathrm{n}=34)$ & $25.31 \pm 6.22$ & $24.92 \pm 5.04$ & $29.16 \pm 8.46$ & $27.07 \pm 6.19$ \\
$(\mathrm{n}=22)$ & $(\mathrm{n}=18)$ & $(\mathrm{n}=14)$ & $(\mathrm{n}=16)$ \\
\hline Experimental group $(\mathrm{n}=37)$ & $28.55 \pm 7.07$ & $28.55 \pm 8.64$ & $30.96 \pm 11.57$ & $24.69 \pm 7.58$ \\
& $(\mathrm{n}=28)$ & $(\mathrm{n}=20)$ & $(\mathrm{n}=14)$ & $(\mathrm{n}=18)$
\end{tabular}

Table 3. Comparison of the web area $\left(\mathrm{cm}^{2}\right)$ between control group and experimental group (mean \pm SD)

\begin{tabular}{lcccc}
\hline & Previous day & Sensory day 1 & Sensory day 2 & Sensory day 3 \\
\hline Control group $(\mathrm{n}=34)$ & $782.75 \pm 247.53$ & $784.62 \pm 172.91$ & $693.38 \pm 292.54$ & $813.05 \pm 360.54$ \\
& $(\mathrm{n}=22)$ & $(\mathrm{n}=18)$ & $(\mathrm{n}=14)$ & $(\mathrm{n}=16)$ \\
\hline \multirow{2}{*}{ Experimental group $(\mathrm{n}=37)$} & $867.16 \pm 396.21$ & $776.64 \pm 271.16$ & $636.49 \pm 381.81$ & $967.45 \pm 559.88$ \\
$(\mathrm{n}=28)$ & $(\mathrm{n}=20)$ & $(\mathrm{n}=14)$ & $(\mathrm{n}=18)$ \\
\hline
\end{tabular}


Table 4. Comparison of the number of spirals between control group and experimental group (mean \pm SD)

\begin{tabular}{lcccc}
\hline & Previous day & Sensory day 1 & Sensory day 2 & Sensory day 3 \\
\hline Control group $(\mathrm{n}=34)$ & $31.14 \pm 7.32$ & $24.28 \pm 8.22$ & $26.00 \pm 7.72$ & $28.94 \pm 5.04$ \\
$(\mathrm{n}=22)$ & $(\mathrm{n}=18)$ & $(\mathrm{n}=14)$ & $23.5)$ \\
\hline Experimental group $(\mathrm{n}=37)$ & $30.16 \pm 8.22$ & $28.45 \pm 9.33$ & $23.57 \pm 10.97$ & $27.72 \pm 9.56$ \\
& $(\mathrm{n}=28)$ & $(\mathrm{n}=20)$ & $(\mathrm{n}=14)$ & $(\mathrm{n}=18)$
\end{tabular}

Table 5. Comparison of the upper stabilimentum length between control group and experimental group ( $\mathrm{cm}$; mean \pm SD)

\begin{tabular}{lcccc}
\hline & Previous day & Sensory day 1 & Sensory day 2 & Sensory day 3 \\
\hline Control group $(\mathrm{n}=34)$ & $\begin{array}{c}2.10 \pm 1.31 \\
(\mathrm{n}=20)\end{array}$ & $\begin{array}{c}2.59 \pm 0.60 \\
(\mathrm{n}=15)\end{array}$ & $\begin{array}{c}1.51 \pm 1.31 \\
(\mathrm{n}=10)\end{array}$ & $\begin{array}{c}1.03 \pm 1.43 \\
(\mathrm{n}=8)\end{array}$ \\
\hline Experimental group $(\mathrm{n}=37)$ & $\begin{array}{c}2.58 \pm 0.95 \\
(\mathrm{n}=22)\end{array}$ & $\begin{array}{c}2.22 \pm 0.44 \\
(\mathrm{n}=15)\end{array}$ & $\begin{array}{c}1.83 \pm 0.65 \\
(\mathrm{n}=6)\end{array}$ & $\begin{array}{c}1.81 \pm 0.56 \\
(\mathrm{n}=10)\end{array}$ \\
\hline
\end{tabular}

Table 6. Comparison of the lower stabilimentum length between control group and experimental group ( $\mathrm{cm}$; mean \pm SD)

\begin{tabular}{lcccc}
\hline & Previous day & Sensory day 1 & Sensory day 2 & Sensory day 3 \\
\hline Control group $(\mathrm{n}=34)$ & $\begin{array}{c}3.51 \pm 0.87 \\
(\mathrm{n}=20)\end{array}$ & $\begin{array}{c}3.50 \pm 0.80 \\
(\mathrm{n}=15)\end{array}$ & $\begin{array}{c}3.24 \pm 0.96 \\
(\mathrm{n}=10)\end{array}$ & $\begin{array}{c}3.22 \pm 0.86 \\
(\mathrm{n}=8)\end{array}$ \\
\hline Experimental group $(\mathrm{n}=37)$ & $\begin{array}{c}3.07 \pm 1.04 \\
(\mathrm{n}=27)\end{array}$ & $\begin{array}{c}2.80 \pm 1.06 \\
(\mathrm{n}=17)\end{array}$ & $\begin{array}{c}1.88 \pm 1.04 \\
(\mathrm{n}=9)\end{array}$ & $\begin{array}{c}3.13 \pm 1.37 \\
(\mathrm{n}=12)\end{array}$ \\
\hline
\end{tabular}

Table 7. Comparison of the total stabilimentum length between control group and experimental group (cm; mean \pm SD)

\begin{tabular}{lcccc}
\hline & Previous day & Sensory day 1 & Sensory day 2 & Sensory day 3 \\
\hline Control group $(\mathrm{n}=34)$ & $\begin{array}{c}7.79 \pm 2.52 \\
(\mathrm{n}=20)\end{array}$ & $\begin{array}{c}6.23 \pm 3.33 \\
(\mathrm{n}=15)\end{array}$ & $\begin{array}{c}7.30 \pm 2.99 \\
(\mathrm{n}=10)\end{array}$ & $\begin{array}{c}6.82 \pm 3.34 \\
(\mathrm{n}=8)\end{array}$ \\
\hline Experimental group $(\mathrm{n}=37)$ & $\begin{array}{c}6.76 \pm 2.60 \\
(\mathrm{n}=27)\end{array}$ & $\begin{array}{c}6.29 \pm 2.78 \\
(\mathrm{n}=17)\end{array}$ & $\begin{array}{c}4.01 \pm 2.87 \\
(\mathrm{n}=9)\end{array}$ & $\begin{array}{c}5.46 \pm 2.76 \\
(\mathrm{n}=13)\end{array}$ \\
\hline
\end{tabular}

하단 흰띠줄 길이의 변화 양상을 관찰한 결과 대조군과 실 험군 모두에서 전반적으로 감소하는 경향이 나타났다(Table 6). 자극 전일과 자극 1 일에 대조군의 경우 평균 길이 $0.01 \mathrm{~cm}$ 감소 경향이 유의미하지 않음을 보였으나(Wilcoxon signed-rank test: $t=1.56, p>0.05)$ 실험군의 경우 평균 길이 0.27 $\mathrm{cm}$ 의 감소 경향을 보였다(t=2.43, $p=0.015)$.

웹의 중앙을 통과하는 흰띠줄 전체 길이를 관찰한 결과 대 조군과 실험군 모두 전반적인 감소 경향이 나타났다(Table 7). 자극 전일과 자극 1 일에 대조군의 경우 평균 길이 $1.56 \mathrm{~cm}$ 의 다소 감소하는 경향을 보였으며(Wilcoxon signed-rank test: $\mathrm{t}=1.96, p=0.051)$, 실험군의 경우 평균 길이 $0.47 \mathrm{~cm}$ 의 감소 경 향을 보였다(t=2.63, $p=0.009)$.

\section{고 찰}

본 연구는 꽃꿀채집자인 서양뒤영벌(Bombus terrestris)의 감
각 정보를 인지한 긴호랑거미(Argiope bruennich)의 웹 건축 빈도가 감각 정보가 제공되지 않은 대조군과 비교해 증가할 것이라는 가설을 제안한 바 있다. 연구 결과 웹 건축 빈도는 대조군과 실험군에서 모두 전반적인 감소 경향을 나타내었다. 오히려 실험군에서 보인 감소 경향이 대조군에 비해 두드러지 게 나타났다. 자극 1 일에 실험군의 웹 건축 빈도가 대조군 감 소 비율의 2 배 감소한 것은 본 연구에서 제시한 가설과 부합하 지 않는 결과를 보이는 것이다.

건축을 포기한 개체의 비율이 상대적으로 많은 실험군에 포함된 일부 개체는 서양뒤영벌(B. terrestris)의 존재에 교란되 었을 가능성이 있을지도 모르겠다. 같은 종의 곤충이라도 웹 에 완전히 걸려들어 움직임이 제한되었을 때는 쉬운 사낭감이 지만 웹에 걸리지 않고 그낭 만났을 때는 때때로 위협적인 존재로서의 역할을 할 수 있기 때문이다[2].

본 연구는 거미의 포식 전략의 하나로 화분 매개자 곤충의 감각 편향을 이용한 유인 기능이 있는 흰띠줄(stabilimentum) 
의 건축은 먹이의 종류에 영향을 받을 것이라는 가설을 제안 하였다. 즉, 자외선 반사에 민감한 서양뒤영벌(B. terrestris)의 정보가 제공된 상황에서 개체는 먹이를 유인하는 흰띠줄 건축 을 시도하는 경향이 증가할 것이라는 것이다. 실험 결과는 당 초의 가설과는 달리 대조군과 실험군에서 모두 흰띠줄의 건축 빈도는 전반적으로 감소하는 경향을 나타내었다. 실험군에서 흰띠줄 건축의 감소는 서론에서 설명한 ‘먹이유인가설'에 부 합하지 않는다.

흰띠줄은 웹 건축에 장식처럼 추가되는 부분이다. 어떤 이 유로 개체가 웹 건축을 포기하거나 미루었다면 흰띠줄의 건축 도 이루어지지 않는다. 흰띠줄 건축 감소를 앞 선 결과인 웹 건축 빈도의 감소와 함께 해석해야 하는 이유이기도 하다. 또 한 흰띠줄을 건축하기 위해 개체는 많은 에너지와 단백질을 투자해야 한다. 실험 기간 중 전반부의 굶긴 기간이 개체의 이러한 투자 능력에 영향을 미쳤을 수 있을 것이다. 하지만 대조군에서는 예외 없이 감소한대 반해 실험군에서 자극 3 일 에 $10.8 \%$ 증가하는 양상을 보인 것은 다른 해석이 필요한 부분 으로 사료된다.

또한 본 연구는 비행성 먹이 정보를 바탕으로 개체는 웹의 높이, 면적, 나선 그물의 수 등에서 차별적인 의사결정을 할 것이라고 예측했었다. 연구 결과는 대조군과 비교했을 때 실 험군에서만 나타나는 특별한 차이를 발견하지 못했다. 웹의 높이가 변화 양상을 보이지 않은 것은 사육 상자의 공간적 제약에 의한 것일 수 있다는 예측이 가능하다. 사육 상자의 높이를 대폭 증가시키는 실험 디자인이 필요한 부분으로 사료 된다. 웹 넓이의 경우 개체가 사육 상자의 공간을 충분히 활용 하지 않고 지은 경우가 대부분이고, 웹 넓이의 증감 양상이 대조군과 실험군 모두에서 뚜렷한 경향성을 가지고 있지 않은 것으로 보여 실험 조건에 크게 영향을 받은 것으로 판단하기 힘든 것으로 사료된다.

연구 결과에서 나타난 자극 3 일째에 전반적인 건축 활동의 증가는, 각 개체에게 있어서 자극 3 일에 해당하는 날짜가 다르 기 때문에 특정일의 기후 조건 따위의 영향을 받은 것으로 보기 어렵다. 두 그룹 모두에서 실험 기간 동안 먹이가 공급되 지 않은 조건에서 포식에 대한 옥구가 강화된 시기로 보는 것이 가능하다고 사료된다.

포식을 위해 웹을 건축할 것인가 아니면 방어를 위해 웹 건축을 미룰 것인가에 관련된 개체의 의사결정을 연구하는데 긴호랑거미(A. bruennich)는 좋은 소재라고 사료된다. 왜냐하 면 그들의 웹은 물리적으로 그들의 의사결정을 잘 반영하기 때문에 각각 웹 구조의 변수가 중요하게 해석될 수 있다. 먹이 유인 보다는 낮게 비행하는 작은 새와 같은 포식자가 있는 상황에서 개체는 눈에 잘 뜨이는 흰띠줄을 만들지 않을 수도 있을 것이다[8].

또한 Blackledge [1]는 낮은 포식 성공도(low foraging success)를 가진 상황에서 거미가 자신의 흰띠줄 건축을 포기할
것이라는 제안을 한 바 있다. 그의 주장은 먹이 곤충이 오히려 흰띠줄의 존재를 인식해서 웹을 피할 것이라는 것이라는 것이 다. 감각 자극만 제공되고 포식 성공이 없는 경우 개체는 먹이 가 피하는 것이라고 생각할 수 있다. 먹이를 유인하기 위해 흰띠줄을 만들 것인가? 아니면 먹이의 눈에 뜨이는 것을 피하 기 위해 흰띠줄을 만들지 않을 것인가? 에 관한 긴호랑거미 $(A$ bruennichi)의 의사결정을 알기 위해서는 더 많은 실험적 접근 이 필요하다.

\section{감사의 글}

본 연구 수행 과정에서 야외 채집을 도와준 김평래, 임승현 학생과 데이터 수집 및 분석을 위해 함께 토의한 김덕래 학생 에게 감사의 마음을 전한다. 본 연구 수행을 위해 동애등에를 무상으로 제공해 준 농촌진흥청 국립농업과학원에 감사한다. 본 연구는 2008년 정부(교육과학기술부)의 재원으로 한국학술 진홍재단(현 한국연구재단)의 지원을 받아 수행된 연구임 (KRF-2008-331-C00270).

\section{References}

1. Blackledge, T. A. 1998. Stabilimentum variation and foraging success in Argiope aurantia and Argiope trifasciata (Araneae, Araneidae). J. Zool. Lond 246, 21-27.

2. Blackledge, T. A. and J. W. Wenzel. 1999. Do stabilimenta in orb webs attract prey or defend spider? Behav. Ecol. 10, 372-376.

3. Bruce, M. J., A. M. Heiling, and M. E. Herberstein. 2004. Web decoration and foraging success in Araneus eburnus (Araneae: Araneidae). Ann. Zool. Fennici 41, 563-575.

4. Craig, C. L. and G. D. Bernard. 1990. Insect attraction to ultra violet-reflecting spider webs and web decorations. Ecology 71, 616-623.

5. Dugatkin, L. A. 2009. Principles of animal behavior. W.W. Norton and Company, New York and London.

6. Daiqin, L. 2005. Spiders that decorate their webs at higher frequency intercept more prey and grow faster. Proc. Biol. Sci. 272, 1753-1757.

7. Herberstein, M. E. and A. F. Fleisch. 2003. Effect of abiotic factors on the foraging strategy of the orb-web spider Argiope keyserlingi (Araneae: Araneidae). Austral Ecol. 28, 622-628.

8. Horton, C. 1980. A defensive function for the stabilimenta of two orb weaving spider (Araneae: Araneidae). Phyche 87, 13-20.

9. Kronk, A. E. and S. E. Riechert. 1979. Parameters Affecting the habitat choice of a desert wolf spider, Lycosa santrita. J. Arachnol. 7, 155-166.

10. Lubin, Y. and J. Henschel. 1996. The influence of food supply on foraging behaviour in a desert spider. Oecologia 105, 64-73. 
11. Morse, D. H. 1999. Choice of hunting site as a consequence of experience in late-instar crab spiders. Oecologia 120, 252-257.

12. Morse, D. H. and R. S. Fritz. 1982. Experimental and observational studies of patch choice at different scale by the crab spider Misumena vatia. Ecology 63, 172-182.

13. Nation, J. L. 2002. Insect physiology and biochemistry. CRC Press.

14. Opell, B. D. 1990. Material investment and prey capture potential of reduced spider webs. Behav. Ecol. Sociobiol. 26, 375-381.

15. Pasquet, A., A. Ridwan, and R. Leborgne. 1994. Presence of potential prey affects web building in an orb-weaving spider Zygiella x-notata. Anim Behav. 47, 477-480.

16. Persons, M. H. and G. W. Uetz. 1996. The influence of sensory information on patch residence time in wolf spiders (Araneae: Lycosidae). Anim Behav. 51, 1285-1293.

17. Persons, M. H. and G. W. Uetz. 1998. Presampling sensory information and prey density assessment by wolf spiders (Araneae: Lycosidae). Behav. Ecol. 9, 360-366.

18. Raine, N. E. and L. Chittka. 2007. The adaptive significance of sensory bias in a foraging context: floral colour preferences in the bumblebee Bombus terrestris. PLos One 2, e556.
19. Riechert, S. E. 1985. Decisions in multiple goal contexts: habitat selection of the spider, Agelenopsis aperta (Gertsch). $Z$. Tierpsychol. 70, 53-69.

20. Rita, H. and G. B. Friedrich. 1983. Vibratory signals: how do the sensory inputs from the eight legs interaction in orientation? J. Comparative Physiol. 152, 361-371.

21. Stephens, D. W., J. S. Brown, and R. D. Ydenberg. 2007. Foraging: behavior and ecology. pp. 608, University of Chicage Press, Chicago and London.

22. Systat, 2007. Systat software Inc.

23. Takeshi, W. 1999. Prey attraction as a possible function of the silk decoration of the uloborid spider Octonobe sybotides. Behav. Ecol. 10, 607-611.

24. Tanaka, K. 1989. Energetic cost web construction and its effect on web relocation in the web building spider Agelena limbata. Oecologia 81, 459-464.

25. Tso, I. M. 1996. Stabilimentum of the garden spider Argiope trifasciata. a possible prey attractant. Anim Behav. 52, 183-191.

26. Wise, D. H. and J. L. Barata. 1983. Prey of two synoptic spiders with different web structures. J. Arachnol. 11, 271-281.

\section{초록 : 먹이 종 감각 정보 제공에 따른 긴호랑거미(Argiope bruennich)의 웹 건축 전략}

진우영 ${ }^{1}$ - 신현철 ${ }^{2}$ - 김길원 ${ }^{1}$ *

( ${ }^{1}$ 인천대학교 자연과학대학 생명과학부, ${ }^{2}$ 한국교원대학교 제 3 대학 화학교육과)

거미의 건축물인 웹의 구조는 먹이 포획을 위한 자원의 투자이자 그 자체가 포식 전략이다. 잠재적인 먹이종으 로부터 제공되는 감각정보를 바탕으로 포식 전략을 수정하는 개체는 그렇지 못한 개체에 비해 더 높은 적응도를 가질 것이다. 본 연구는 공중에 둥근 웹을 건축하는 긴호랑거미(Argiope bruennichi)를 대상으로 자외선을 인식하 는 비행성 곤충인 서양뒤영벌 (Bombus terrestris)의 정보를 경험한 개체가 자신의 건축 행동을 수정하는지를 알아 보기 위해 수행되었다. 서양뒤영벌(B. terrestris)의 정보를 제공받은 실험군의 개체가 건축한 웹의 구조를 대조군 (정보 없음)의 웹과 비교하였다. 본 연구의 가설은 실험군 개체들은 웹과 흰띠줄 건축에 더 많은 투자를 할 것이 라는 것이다. 실험 결과는 당초의 가설을 기각했다. 웹과 흰띠줄 건축은 실험군과 대조군 모두에서 전반적으로 감소하는 경향을 나타냈다. 개체는 꽃꿀채집자의 정보에도 불구하고 흰띠줄을 더 길게 만들지도 웹을 확장하지 도 않았다. 